\title{
Examining the Roles of Self-Efficacy Beliefs, Self-Regulated Learning and Foreign Language Anxiety in the Academic Achievement of Tertiary EFL Learners
}

\author{
Omer Ozer* \\ Department of Translation and Interpreting Faculty of Humanities and Social Sciences \\ Adana Alparslan Türkeş Science and Technology University, Turkey \\ ORCID: 0000-0001-8502-3145 \\ Duygu İşpınar Akçayoğlu \\ Department of Translation and Interpreting Faculty of Humanities and Social Sciences \\ Adana Alparslan Türkeş Science and Technology University, Turkey
}

ORCID: 0000-0001-9031-5011

\begin{tabular}{ll}
\hline \hline Article history & This quantitative study investigates the potential relationships among \\
Received: & foreign-language self-efficacy (FL self-efficacy), self-regulation, \\
foreign-language anxiety (FLA), class attendance and academic & achievement in English language. The participants were 344 EFL \\
Received in revised form: & learners who were enrolled in a one-year preparatory programme at a \\
24.11 .2020 & state university in Turkey to improve their overall English proficiency. \\
Accepted: & Criterion sampling was used to select the respondents. The results \\
01.12 .2020 & indicate that class attendance significantly predicts the overall academic \\
Key words: & achievement of students. It is also striking to see that FL self-efficacy \\
individual differences, & played the most significant and positive role in predicting EFL learners' \\
FL self-efficacy, & academic achievement. Moreover, FLA was a negative predictor of \\
Self-regulation, & students' academic performance. Therefore, students' FL achievement \\
Foreign-language anxiety, & decreases as anxiety increases. The study shows that class attendance is \\
Class attendance, & still a strong predictor of academic achievement in foreign language \\
Academic achievement, & learning. In addition, self-regulated learning (SRL) reflected a significant \\
Turkish EFL students & increase in class attendance. The findings also confirm the correlations \\
& among the three constructs. The analysis yielded a medium negative \\
& correlation between FL self-efficacy and FLA in addition to a small \\
positive correlation between FL self-efficacy and SRL. Given the & growing role of blended and online learning, we advocate for the \\
publication of more studies with longitudinal research designs examining \\
the inter-relations among SRL, academic performance and attendance in \\
online and 'traditional' classrooms. The implications of the findings for \\
teachers and language learners are also discussed.
\end{tabular}

*Correspondency: ozeromer.tr@gmail.com 


\section{Introduction}

The journey of learning a foreign language can be a frustrating and distressing experience for some learners (Ryan \& Deci, 2009; Shirvan \& Talebzadeh, 2018) and could depend largely on individual differences that have been investigated in the literature from various aspects and in various contexts not only by socio-demographic variables but also by affective factors such as anxiety, motivation, personality, and self-efficacy (Kim, Wang, Ahn \& Bong, 2015). There is a growing body of literature suggesting that self-efficacy (Honicke \& Broadbent, 2016; Mills, Pajares \& Herron, 2007; Raoofi, Tan \& Chan, 2012; Sarıçoban \& Behjoo, 2016; Wang, Kim, Bai \& Hu, 2014) and self-regulation (Bai \& Wang, 2020; Seker, 2016; Yabukoshi, 2018) contribute to language learning. Continued research into anxiety has also emphasized that FLA is a complex affective factor in language learning (Hewitt \& Stephenson, 2012; Woodrow, 2006; Yan \& Horwitz, 2008). Academic performance in learning a foreign language could also be predicted by factors such as self-efficacy, self-regulation, and anxiety.

Bandura (1994) defined self-efficacy as "people's beliefs about their capabilities to produce designated levels of performance that exercise influence over events that affect their lives" ( $p$. 2). He also highlighted that self-efficacy beliefs determine the ways in which people feel, think, motivate themselves and behave. Whereas high self-efficacy enhances human accomplishment and personal well-being and helps people to approach difficult tasks as challenges to be mastered (Wang, Harrison, Cardullo \& Ling, 2018), low self-efficacy causes individuals to shy away from difficult tasks and to see them as personal threats, which causes them to give up quickly (Bai, Chao \& Wang, 2019). Self-efficacy has been investigated in various foreignlanguage learning contexts such as in the context of pre-service EFL teachers (Choi \& Lee, 2018; Çakır \& Alıc1, 2009; Thompson \& Woodman, 2019), in the context of EFL learners in compulsory preparatory language programmes (Demirdaş \& Bozdoğan, 2013; Kesen-Mutlu, Andarab \& Karacan, 2019), in the context of high-school students studying English as a foreign language (Fryer \& Oga-Baldwin, 2017; Passiatore, Pirchio, Oliva, Panno \& Carrus, 2019) and in the context of academics from various disciplines (Pasupathy \& Siwatu, 2014; Reyes-Cruz \& Perales-Escudero, 2016). In a review study which included studies on self-efficacy in foreign-language learning, Raoofi et al. (2012) concluded that self-efficacy was a strong predictor of performance in reading and listening skills in particular and success in various learning tasks. If teachers can get the students to have repeated experiences of success, this can help students to foster positive beliefs about their abilities. Students who had high self-efficacy levels have been found to be significantly more self-regulated (Kim et al., 2015) and as they become self-regulated learners, they start to apply some SRL strategies such as meta-cognitive self-regulation preventing information overload (Bai \& Wang, 2020). Therefore, self-efficacy has been reported to be associated with cognitive strategy use (Liem, Lau \& Nie, 2008). Thus, self-efficacious students are significantly more self-regulated (Kim et al., 2015) and tend to sustain their efforts until they accomplish what they set out to do.

Horwitz, Horwitz and Cope (1986) defined foreign-language classroom anxiety as "a distinct complex of self-perceptions, beliefs, feelings, and behaviours related to classroom language learning arising from the uniqueness of the language learning process" (p. 128). Studies in the literature have reported a negative correlation between high levels of anxiety and language achievement and performance (Demirdaş \& Bozdoğan, 2013; Hewitt \& Stephenson, 2012; Salehi \& Marefat, 2014; Woodrow, 2006; Zheng \& Cheng, 2018). The influence of FLA on academic performance in a foreign language is quite complex, that is, students with high levels of FLA generally exhibit a lower level of proficiency in English, whereas low achievement could be also a cause of FLA (Trang, Baldauf Jr., \& Moni, 2013). Like FLA, self-regulation 
strategies in language learning has been a popular topic of research for the last two decades. However, unlike FLA, the effect of SRL on academic performance is positive.

Schunk (2001) defined self-regulated learning as "learning that results from students' selfgenerated thoughts and behaviours that are systematically oriented toward the attainment of their learning goals" (p. 125). It is a highly-regarded, key life-long-learning competence in learners acquiring subject content knowledge both at school and in life (Gan, Liu \& Yang, 2020). Self-regulated learning has been reported to be a significant predictor of foreignlanguage achievement and performance, and this relationship has been documented in several research studies across the world (e.g. Choi, Zhang, Lin \& Zhang, 2018; Fukuda, 2018; Seker, 2016; Shing \& Rameli, 2020). Some of the characteristics self-regulated learners reportedly share are self-awareness, competency, and self-judgment (Kim et al., 2015; Schunk, 2001). In the absence of these features, learners are thought to be less motivated and are likely to display poor academic performance. Self-regulatory skills are acquired through a process of social modelling, guidance, collaboration, and feedback (McInerney, 2008).

Despite the growing number of studies, there have been no studies yet designed to examine the triple relationship between self-efficacy in English, self-regulation, and anxiety in predicting language learners' ultimate achievement results in in-year assessment and overall class attendance. In language learning, the relationship between individual differences and academic performance is considered highly complex and context specific (Piniel \& Csizér, 2013), so this study attempts to find some compelling evidence to suggest that these variables not only have an impact on academic achievement, but also they are interrelated. In the current study, three different measures were used to reflect students' learning-related beliefs and strategies, and it was hypothesised that these constructs would help us to predict the attendance rates and academic performance which students have at the end of the autumn term. A vast number of studies have identified FL self-efficacy (Bai et al., 2019; Ferla, Valcke \& Cai, 2009; Honicke \& Broadbent, 2016; Mills et al., 2007; Sarıçoban \& Behjoo, 2016) and FLA (Hewitt \& Stephenson, 2012; Woodrow, 2006; Zheng \& Cheng, 2018) as predictors of academic performance. Based on the findings of some studies from different educational settings (Bai et al., 2019; Honicke \& Broadbent, 2016; Raoofi et al., 2012), it was also hypothesised that selfefficacy would be the strongest predictor of academic achievement.

Lectures have customarily been the predominant mode of instruction in face-to-face tertiary level courses and most previous research to date has shown that students with high attendance rates are often credited with higher academic achievement than their counterparts with low attendance (Credé, Roch \& Kieszczynka, 2010; Kelsen \& Liang, 2012; Nyamapfene, 2010). It was hypothesised in this study that class attendance is still a strong predictor of academic achievement in the English language despite the fact that students now have greater opportunities and easy access to digital materials and technologies to learn a foreign language anywhere, anytime. In addition, it was hypothesised that FLA would negatively correlate with FL self-efficacy, SRL and academic achievement.

At the beginning of their formal training, most EFL learners generally show a willingness to learn, but this genuine willingness might go into a gradual decline over time as they spend time at school (Cheng \& Lee, 2018; Csapó, 2007; Ryan \& Deci, 2009). The decreasing trend of willingness among students may have many reasons including learning-related beliefs and can be attributed to a large number of factors including self-efficacy, self-regulation, anxiety and a lack of an autonomous attitude (Bai \& Wang, 2020; Cheng \& Lee, 2018; Ghonsooly \& Ghanizadeh, 2013; Mills et al., 2007; Yabukoshi, 2018; Yan \& Horwitz, 2008). Identifying the 
factors which affect academic achievement is a core phenomenon of interest in educational research. However, the number of previous studies is small, and little is still known about the absenteeism and even the drop-out behaviours of students learning English as a foreign language at tertiary level. There is no denial that lecture attendance as well as attendance in other teaching modalities has a positive impact on student learning (Credé et al., 2010; Gottfried, 2009; Kelsen \& Liang, 2012; Nyamapfene, 2010). Thus, it is important to examine the attendance rates of language learners in the Turkish context.

This study was also inspired by the fact that there seems to have been little research so far investigating how EFL learners' language progress is predicted by class attendance and selfregulation or seeking to understand the possible relationships between FL self-efficacy, SRL and FLA to predict attendance and achievement. The purpose of this correlational study is, therefore, to evaluate the associations between the variables and to identify which of FL selfefficacy, SRL, FLA and class attendance is the strongest predictor of academic achievement among tertiary EFL learners at an English-Medium Instruction (EMI) university in Turkey. Identifying the possible relationships between these variables will provide important insights into the performance of FL learners. This study is therefore designed to address the following research questions:

$\mathrm{RQ}_{1}$. Of FL self-efficacy, SRL and FLA, which variable is the strongest predictor of academic achievement?

$\mathrm{RQ}_{2}$. Is class attendance a significant predictor of academic achievement?

$\mathrm{RQ}_{3}$. Are FL self-efficacy, SRL and FLA significant predictors of class attendance?

$\mathrm{RQ}_{4}$. Is there any statistically significant relationship among FL self-efficacy, SRL and FLA?

\section{Method}

This study combined the explanatory and prediction designs of correlational research. The study was therefore quantitative and non-experimental in nature since its intention was to understand whether an increase or decrease in each variable predicted or corresponded to a change in EFL learners' academic achievement (Creswell, 2012).

\section{Participants}

The sample group in the current study comprised 344 EFL students, with a mean age of 19.13 years (range $=18-32 ; \mathrm{SD}=1.42$ ), from a medium-scale, research-oriented state university in the south of Turkey. Most of the programmes offered at the university are full-EMI although a small number of other programmes are offered in partial EMI, and all incoming students, regardless of their degree programmes, have to participate in the Preparatory Year English Language Programme (PYP) unless they get a passing score in an in-house English proficiency examination. The PYP, an intensive tuition in English for a term or two, is designed to help students to gain sufficient linguistic skills before commencing their chosen field of study (Macaro \& Akincioglu, 2018; Ozer, 2020). The participants were therefore all PYP across various engineering disciplines (science-related programmes) and a few social science disciplines (social-related programmes). The research team visited all classes in the given term in an attempt to reach the entire student body who were at the A1 level of proficiency in English. Therefore, a non-probability criterion sampling technique was used to enlist the participation of students at the A1 level of English only. Students who did not meet the proficiency criterion, in this case being at the A2 or at a higher level of English proficiency according to the CEFR guidelines at the beginning of the autumn term, were excluded from the study. Table 1 provides the demographic variable distributions. 
Table 1. Demographic results related to the participants

\begin{tabular}{llll}
\hline Variable & Descriptor & n & \% \\
\hline Gender & Female & 124 & 36.0 \\
& Male & 220 & 64.0 \\
Subject & Science-related (engineering, architecture) & 197 & 57.3 \\
& Social-related (business administration, political sciences) & 147 & 42.7 \\
Class status & 314 & 91.3 \\
& PYP & 30 & 8.7 \\
\hline
\end{tabular}

\section{Research Instruments}

The present study made use of three scales, two of which, namely the Self-Regulation Questionnaire (Brown, Miller \& Lawendowski, 1999) and the Foreign Language Classroom Anxiety Scale (Horwitz et al., 1986) were the Turkish versions of instruments originally developed using U.S. samples. The main reason for employing the selected scales was that they have been utilised in diverse range of research studies. There are also more recent scales of SRL (Erdogan \& Senemoglu, 2016) or FLA (Alkan, Bümen \& Uslu, 2019; Yağı, 2018) developed or adapted for the Turkish population, but the researchers did not use them in the study either due to the large number of items in the measure or due to skill-specific nature of the scales.

\section{FL self-efficacy scale}

To assess students' FL self-efficacy, the scale developed by Hanc1-Yanar and Bümen (2012) was used. The Cronbach's alpha coefficient was calculated to be 0.96 for the overall scale; 0.88 for the reading sub-scale, 0.87 for the writing sub-scale, 0.91 for the listening subscale and 0.86 for the speaking sub-scale. The 34-item instrument consists of statements which require responses on a five-point Likert scale ranging from 5 ('totally agree') to 1 ('totally disagree'). In the present study, internal consistency reliability was assessed, and Cronbach's alpha results indicated excellent internal consistency $(\alpha=.96)$ for the scale.

SRL scale

A Turkish adaptation of the self-regulation questionnaire that was developed by Brown et al. (1999) was used in the current study. The instrument was adapted to the Turkish context in a sample of undergraduate students (Aydin et al., 2014). The adapted scale, with a coefficient alpha of .87, is a 51-item instrument with responses based on a five-point Likert scale ranging from 5 ('strongly agree') to 1 ('strongly disagree'). In this study, the internal consistency was determined as .94 .

\section{FLA scale}

In the present study, FL anxiety was measured using a Turkish adaptation of the Foreign Language Classroom Anxiety Scale (FLCAS) originally developed by Horwitz et al. (1986). The Turkish version of the FLCAS was a 33-item measure with a .86 Cronbach's alpha (Aydin et al., 2016). The items are scored on a five-point Likert scale ranging from 'strongly agree' to 'strongly disagree'. In the present study, the internal consistency was $\alpha=.94$ for the scale.

\section{Data Collection and Analysis}

The study took place during the autumn term of the 2019-2020 academic year. Data were collected from October 2019 to January 2020 in two steps. First, research and ethical approval were obtained from the Research and Publication Committee on Ethics at the selected 
state university in the south of Turkey. Second, the researchers visited the classes one by one and informed the students that participation in the study was voluntary. The students, who agreed to take part in the study, filled out the questionnaires during regular school hours in their classrooms. The students were also assured of the confidentiality of their responses. With students' informed consent, their academic records were obtained from the school administration at the beginning of the second term to ascertain their grades and class attendance record.

In language schools, it is important to place students into appropriate levels to ensure that instruction is well-targeted to the students' needs. Therefore, ensuring the homogeneity of the sample in this study was of utmost importance in terms of data quality. The homogeneity was ensured by including the students who were placed into A1-level groups. This enabled the research team to hypothesise that participants' baseline scores were homogeneous in the majority with respect to English language proficiency. With students' scores on the three measures collected at the beginning of the term and their attendance and achievement records collected at the end of the term, the research team had a favourable opportunity to identify changes regarding how students' levels of self-efficacy, SRL and FLA could have been involved in their attendance and achievement by the end of the term.

Academic achievement in this study is a total score calculated using students' scores on quizzes, oral presentations, writing portfolio, self-paced online assignments, and midterm examinations throughout the autumn term. 'Class attendance' in this study, on the other hand, refers to the number of classes from which each student was absent over the autumn term.

Initially, there were 470 respondents, but some of the students later did not want to disclose their responses or others did not complete the full term, so their academic performance could not be assessed. Responses found not to be complete were not used in the statistical analyses. The data collected from the respondents were analysed using IBM SPSS Statistics version 22. Data were checked for normality of distribution. Pearson $r$ correlation and descriptive statistics were used as the distributional assumptions were not violated. None of the variables were significantly skewed or kurtotic, and the data met the assumptions of regression, so simple linear regressions were performed in order to answer the first three research questions.

\section{Results}

Overall, the results reveal that the participating EFL students showed moderate levels of anxiety $(\mathrm{M}=2.71 ; \mathrm{SD}=.66), \mathrm{SRL}(\mathrm{M}=172.99 ; \mathrm{SD}=27.34)$ and self-efficacy $(\mathrm{M}=3.03$; $\mathrm{SD}=.61)$. The mean academic achievement for the sample was $68.62(\mathrm{SD}=13.65)$ and the mean absentee rate was 51.91 hours $(\mathrm{SD}=28.26)$. In order to answer research question 1 , a simple linear regression was carried out to investigate the relationships between the scores on the FL self-efficacy, SRL, FLA instruments, and on academic achievement.

Table 2. Regression Analyses between FL self-efficacy and Academic Achievement

\begin{tabular}{lllll}
\hline Variable & B & $\boldsymbol{\beta}$ & $\mathbf{t}$ & $\mathbf{p}$ \\
\hline Constant & 47.351 & & 13.411 & .000 \\
FL self-efficacy & 7.008 & .315 & 6.144 & .000 \\
\hline
\end{tabular}

* Dependent variable: academic achievement

$* * \mathrm{R}^{2}=.099$

The simple linear regression showed a statistically significant relationship between FL selfefficacy and EFL learners' academic achievement $(\mathrm{F}(1 ; 342)=37.752, \mathrm{p}=.000<.05)$. Thus, a 
positive increase in the FL self-efficacy reflected a positive increase in academic achievement in FL. The $\mathrm{R}^{2}$ value was .099 so $9.9 \%$ of the variance in academic achievement scores can be explained by a model containing only the scores on FL self-efficacy.

Table 3. Regression Analyses between SRL and Academic Achievement

\begin{tabular}{lllll}
\hline Variable & $\mathbf{B}$ & $\boldsymbol{\beta}$ & $\mathbf{t}$ & $\mathbf{p}$ \\
\hline Constant & 60.579 & & 12.871 & .000 \\
SRL & 2.369 & .093 & 1.729 & .085 \\
\hline
\end{tabular}

* Dependent variable: academic achievement

$* * \mathrm{R}^{2}=.009$

The simple linear regression showed no statistically significant relationship between SRL and academic achievement $(\mathrm{F}(1 ; 342)=2.989, \mathrm{p}=.085<.05)$.

Table 4. Regression Analyses between FLA and Academic Achievement

\begin{tabular}{lllll}
\hline Variable & $\mathbf{B}$ & $\boldsymbol{\beta}$ & $\mathbf{t}$ & $\mathbf{p}$ \\
\hline Constant & 84.348 & & 28.276 & .000 \\
FLA & -5.809 & -.282 & -5.429 & .000 \\
\hline
\end{tabular}

* Dependent variable: academic achievement

$* * \mathrm{R}^{2}=.079$

The simple linear regression showed a negative correlation between FLA and EFL learners' academic achievement $(\mathrm{F}(1 ; 342)=29.469, \mathrm{p}=.000<.05)$. Therefore, academic achievement decreased by -.282 for every point increase in FLA score. The $\mathrm{R}^{2}$ value was .079 so $7.9 \%$ of the variance in academic achievement scores can be explained by a model containing only the scores on FLA.

The second research question asked whether class attendance is a statistically significant predictor of academic achievement. A simple linear regression was calculated to predict academic achievement based on class attendance.

Table 5. Regression Analyses between Class Attendance and Academic Achievement

\begin{tabular}{lllll}
\hline Variable & $\mathbf{B}$ & $\boldsymbol{\beta}$ & $\mathbf{t}$ & $\mathbf{p}$ \\
\hline Constant & 82.090 & & 63.066 & .000 \\
SRL & -.260 & -.537 & -11.781 & .000 \\
\hline
\end{tabular}

* Dependent variable: academic achievement

$* * \mathrm{R}^{2}=.289$

A significant regression equation was found $(\mathrm{F}(1 ; 342)=138.800, \mathrm{p}=.000<.05)$, with an $\mathrm{R}^{2}$ of .289. Respondents' predicted academic achievement was equal to $82.090+-.260$ class attendance when attendance was measured in the number of class hours. The $\mathrm{R}^{2}$ value was .289 so $28.9 \%$ of the variance in academic achievement scores can be explained by a model containing only the students' attendance rates.

In order to answer the third research question, the data were subjected to a simple linear regression analysis to determine whether EFL learners' scores on FL self-efficacy, SRL and FLA could predict a decrease in class attendance. A simple linear regression did not reveal a correlation between mean FL self-efficacy and class attendance $(\mathrm{r}=.006, \mathrm{~F}(1 ; 342)=.014, \mathrm{p}=$ $.904)$ or between mean FLA and class attendance $(\mathrm{r}=.026, \mathrm{~F}(1 ; 342)=.239, \mathrm{p}=.625)$. 
Table 6. Regression Analyses between SRL and Class Attendance

\begin{tabular}{lllll}
\hline Variable & $\mathbf{B}$ & $\boldsymbol{\beta}$ & $\mathbf{t}$ & $\mathbf{p}$ \\
\hline Constant & 73.321 & & 7.547 & .000 \\
SRL & -6.312 & -.120 & -2.231 & .026 \\
\hline
\end{tabular}

* Dependent variable: class attendance

$* * \mathrm{R}^{2}=.014$

The simple linear regression showed a statistically significant relationship between SRL and EFL learners' class attendance $(\mathrm{F}(1 ; 342)=4.978, \mathrm{p}=.026<.05)$. Thus, a positive increase in the SRL reflected a positive increase in class attendance rates. Based on the $\mathrm{R}^{2}$ value, it can be claimed that $1.4 \%$ of the variance in class attendance rates can be explained by a model containing only the scores on SRL.

In order to answer the fourth research question, the strength and direction of the linear relationships between the means on the scales were calculated. A correlation matrix for the FL self-efficacy, SRL and FLA variables showing the correlation coefficients calculated using the statistical formula for Pearson $\mathrm{r}$ is presented in Table 7.

Table 7. Correlation Matrix for Pearson $r$

\begin{tabular}{llrrr}
\hline & & FL self-efficacy & SRL & FLA \\
\hline FL self-efficacy & Pearson correlation & 1 & .135 & -.398 \\
& Sig. (2 tailed) & & .012 & .000 \\
SRL & N & 344 & 344 & 344 \\
& Pearson correlation & & 1 & -.084 \\
\multirow{4}{*}{ FLA } & Sig. (2 tailed) & & 344 & .122 \\
& N & & & 344 \\
& Pearson correlation & & & 1 \\
& Sig. (2 tailed) & N & & 344 \\
\hline
\end{tabular}

* 2-tailed

The Pearson's correlation coefficients showed a medium negative correlation between FL selfefficacy and FLA $(r=-.398, p=.000)$ and a small positive correlation between FL self-efficacy and SRL $(\mathrm{r}=.135, \mathrm{p}=.012)$ (George \& Mallery, 2019).

\section{Discussion}

In response to the first research question, FL self-efficacy was found to be the strongest predictor of academic achievement and this result corroborated previous findings of Ferla et al. (2009), Honicke and Broadbent (2016), Sarıçoban and Behjoo (2016) and Wang et al. (2014). Moreover, the analysis indicated FLA to be a significant predictor of achievement in FL, and it inversely predicted academic performance. Therefore, students' FL achievement decreases as anxiety increases. Our results are in line with those of Hewitt and Stephenson (2012) and Zheng and Cheng (2018) indicating a negative correlation between FLA and students' FL achievement and also with Woodrow's (2006) result also pointing out a significant negative relationship between FLA and oral achievement in the second language. This discussion implies that if teachers can empower students to become more autonomous and self-efficacious, there will be not only more students with low anxiety (Alrabai, 2015), but also more students who display better academic performance (Hewitt \& Stephenson, 2012).

With regard to the second research question concerning the predicted effect of class attendance on academic achievement, a significant regression equation was found. The regression model containing only class attendance significantly predicted $28.9 \%$ of the achievement of the students. Given that attendance is so strongly associated with academic achievement, teachers 
should try to improve and maintain high class attendance rates. The current study is one of the few empirical investigations into the predictive role of class attendance in English language proficiency. Other researchers who found evidence with respect to the association between attendance and achievement include Kelsen and Liang (2012) in a sample of Taiwanese EFL learners and Nyamapfene (2010) in a sample of undergraduate students in the UK. It is vital for teachers to observe their students' progress closely and to try to understand the reasons causing low class attendance in their group given that attendance is a key determinant for students' achievement in FL. The pandemic faced by the world today reminds us again of the fact that (online) school attendance during the crisis is as important as at any other time and that teachers should work hard to keep students engaged. Nyamapfene (2010) suggested that if teachers view the learning process as a socio-cognitive phenomenon and try to establish a socio-cognitive environment, then students' academic performance will be positively impacted.

With respect to the third research question on whether class attendance could be predicted by FL self-efficacy, SRL and FLA, the findings highlight that SRL reflected a positive increase in class attendance rates. Further to these findings, the students' mean on SRL explains only a small proportion of the variance of class attendance, and therefore predicting attendance based on SRL measures only is fraught with difficulties. Even though few studies on SRL have examined its effect on class attendance, this finding of the current study aligns well with the previous finding from a longitudinal study carried out with the participation of $300 \mathrm{EFL}$ students by Yan and He (2019).

Results from the correlation analyses suggest that FL self-efficacy is positively correlated with SRL and we note that this result corroborates previous studies concerning the relationship between self-efficacy and self-regulation carried out by Ghonsooly and Ghanizadeh (2013) and by Sarıçoban and Behjoo (2016). This might also be indicative of the fact that when teachers use strategies to promote self-regulation, students' self-efficacy beliefs are likely to be raised as well. It was also found in this study that FL self-efficacy was significantly negatively correlated with FLA. When teachers manage to make FL learners more self-efficacious, they will possibly be able to help their students to suffer less from FLA. Jee (2018) also identified a negative correlation between self-efficacy and anxiety in a sample of Korean-as-a-foreignlanguage students in a public university in Australia. The finding of this current study also supports those of Bensalem (2018) and Shirvan, Khajavy, Nazifi and Taherian (2018) in a longitudinal study.

\section{Conclusion}

The results of this study highlighted the potential correlations among FL self-efficacy, SRL, FLA, class attendance and academic achievement. The findings suggest that EFL learners who demonstrate high levels of FL self-efficacy are also the students reporting lower levels of FLA. First, teachers should be highly observant of their students' learning process and should design learning environments to enhance students' FL self-efficacy beliefs. As FL self-efficacy and SRL are also correlated, this highlights the importance of teachers' success in their attempts to give their students learning experiences which help them to self-regulate their learning. The results also show that SRL is significantly correlated with class attendance and therefore selfregulated EFL learners are also likely to improve their class attendance rates. Furthermore, class attendance is a strong predictor of academic achievement and approximately $30 \%$ of the variance for academic achievement is explained by the variance of attendance only based on the regression model. Absenteeism may lead to students' falling short of experience of in-class skill practice, peer interaction and learning materials. This is an effect which should not be 
overlooked, so teachers should employ a process approach, thereby encouraging class attendance. Additionally, the results showed that higher levels of FL self-efficacy and lower levels of FLA promote positive learning experiences and were found to be significant predictors of higher academic achievement. The understanding of the relationship between FL selfefficacy, SRL, FLA, class attendance and academic achievement presents significant implications for foreign language teaching and learning. Given that there exists a notable negative correlation between FL self-efficacy and FLA and many EFL learners suffer some degree of anxiety early on in their education (Jee, 2018; Kim et al., 2015), language teachers should promote students' sense of self-efficacy by enriching reflective processes, providing individual mentoring, encouraging their use of problem-solving skills and so on. Teachers can also provide task-oriented or situation-specific appraisals to the learners by also keeping always in mind that self-efficacy is a domain-specific construct. Therefore, high self-efficacy could lead to better academic performance in English language. Based on the findings of this study, it can be recommended that language teachers should take these variables into account in order to provide their students with a more motivating learning experience in which they can take more active responsibility for their learning.

\section{Implications for Teaching and Learning}

Today, many students might be aware of the intensifying need to learn a foreign language, but they might not be using their full potential given that language learning is a complex process. To assist them to reach their potential, language teachers should accept the role of facilitator and guide and they should closely observe students in order to help them to diagnose their needs and thus help them to discover their own solutions by giving them guidance and encouragement. A large body of research has shown that a substantial number of students underachieve in FL classrooms due to FLA (Amiri \& Ghonsooly, 2015; Hewitt \& Stephenson, 2012), have low self-efficacy beliefs in learning a foreign language (Busse \& Walter, 2013; Mills et al., 2007) or lack self-regulation skills (Fukuda, 2018; Seker, 2016). Therefore, the debilitating effects of these variables on the learning process should be minimised-if not eliminated- and this requires the active involvement of teachers. Language teachers need to employ a proactive approach and implement techniques to reduce students' anxiety as well as to look for ways to help students to enhance their FL self-efficacy and develop their self-regulation skills. Teachers' anxiety reducing strategies should concentrate on understanding students' anxiety-provoking situation and on the efforts to overcome their anxiety (Alrabai, 2015). One of the best resources for a teacher will be a less stressful language learning environment. Considering the positive relationship between SRL and class attendance, students with developed self-regulation skills are likely to attend classes more regularly and their academic achievement will improve as a result (Nyamapfene, 2010). Because levels of SRL explain only a small proportion of the variance in class attendance, predicting attendance based on SRL measures only is fraught with difficulties. Stating this does not deny the importance of SRL strategies as employed by learners but requires further evidence from different contexts in the future. Given that class attendance significantly predicts the overall academic success of EFL students, teachers might employ a process approach in order to encourage class attendance. Even though the advantages of process approach to teaching writing and speaking in a foreign language classroom have been well acknowledged in a large number of studies (Graham \& Perin, 2007; Huang \& Zhang, 2020; Munira, 2017; Ozer \& Tanriseven, 2016), applying a process-based approach to the receptive skills is not as simple as it sounds. Fortunately, there are many other principles that teachers can apply to improve class attendance such as boosting personalised learning and offering extracurricular activities to incorporate collaboration in the classroom (Nyamapfene, 2010). Essentially, language teachers 
need to closely observe their students' level of self-efficacy and SRL and to be keenly aware of students' ongoing skill-specific anxieties (Torres \& Turner, 2016). Given that interrelated nature of these variables, language teachers should always be on the alert for any student for whom it is hard to speak and understand the messages of his/her peers because communication apprehension might be an indicator of foreign language anxiety, and so is the fear of negative social evaluation (Hewitt \& Stephenson, 2012; Horwitz et al., 1986). Teachers should also prevent students from being exposed to too many negative experiences such as being laughed at when failing to pronounce a word correctly. These sorts of problems can be seen at any education level and in any mode of teaching, and online education is no exception. In online teaching, teachers' educational psychology knowledge, communication skills, teaching style, problem-solving skills and classroom management skills are all put to a gruelling test. Students, who tend to have a feeling of isolation in a physical classroom, could even feel more separated from their classmates in a virtual language classroom and the teacher's expertise in supervising relationships and behaviours of his/her students should be brought into play to handle this sort of issue.

\section{Limitations and Future Directions}

Several limitations of this study should be noted. First, the data on FL self-efficacy, SRL and FLA relied only on students' self-reports. As a result of students' self-reports, the results might be influenced by social desirability bias. Second, the students' prior achievements were not used as a covariate in the current study. Future studies should assess the associations based on longitudinal data gathered over a period of two terms. They should also collect data by multiple methods such as lesson observation of teachers and face-to-face interviews with students to complement the quantitative data. Furthermore, some students with very low attendance rates did not complete the term because students who were not present at more than $20 \%$ of total classes during an academic year were not allowed to take part in the final examination. Therefore, those students opted for dropping out of school at a point during the term and their data were incomplete and were excluded from the study. Finally, this study was not observational and was based on a set of data collected at one university only, and consequently requires replication and confirmation through mixed-methods research to be conducted in a wider range of institutions. Thus, research should continue to examine the interrelations among SRL, attendance in online and traditional classrooms and academic performance using longitudinal research designs. Cross-cultural studies can be adopted to investigate whether students' learning behaviours can be observed in a similar fashion in different cultures.

\section{References}

Alkan, H., Bümen, N., \& Uslu, N. (2019). İngilizce konuşma kaygısı ölçeği’nin Türkçeye uyarlanma çalışması [Adaptation of the second language (English) speaking anxiety scale into Turkish]. Gazi University Journal of Gazi Educational Faculty, 39(2), 11571180 .

Alrabai, F. (2015). The influence of teachers' anxiety-reducing strategies on learners' foreign language anxiety. Innovation in Language Learning and Teaching, 9(2), 163-190. https://doi.org/10.1080/17501229.2014.890203

Amiri, M., \& Ghonsooly, B. (2015). The relationship between English learning anxiety and the students' achievement on examinations. Journal of Language Teaching and Research, 6(4), 855-865. http://dx.doi.org/10.17507/j1tr.0604.20 
Aydın, S., Harputlu, L., Güzel, S., Savran-Çelik, Ş., Uştuk, Ö., \& Genç, D. (2016). A Turkish version of foreign language anxiety scale: Reliability and validity. In İ. H. Mirici, İ. H. Erten \& H. Öz (eds.), International Conference on Teaching and Learning English as an Additional Language, GlobELT 2016, Vol: 232 (pp. 250-256). https://www.sciencedirect.com/science/article/pii/S1877042816312435

Aydın, S., Özer-Keskin, M., \& Yel, M. (2014). Öz-düzenleme ölçeğinin Türkçe uyarlaması: Geçerlik ve güvenirlik çalışması [Turkish adaptation of the self-regulation questionnaire: a study on validity and reliability]. Turkish Journal of Education, 3(1), 24-33. http://doi.org/10.19128/turje.181073

Bai, B., Chao, G. C. N., \& Wang, C. W. (2019). The relationship between social support, selfefficacy, and English language learning achievement in Hong Kong. TESOL Quarterly, 53(1), 208-221. https://doi.org/10.1002/tesq.439

Bai, B., \& Wang, J. (2020). The role of growth mindset, self-efficacy and intrinsic value in selfregulated learning and English language learning achievements. Language Teaching Research. https://doi.org/10.1177/1362168820933190

Bandura, A. (1994). Self-efficacy. In V.S. Ramachaudran (ed.), Encyclopedia of human behavior (Vol. 4, pp. 71-81). New York: Academic Press.

Bensalem, E. (2018). Foreign language anxiety of EFL students: Examining the effect of selfefficacy, self-perceived proficiency and sociobiographical variables. Arab World English Journal, 9(2), 38-55. https://dx.doi.org/10.2139/ssrn.3201901

Brown, J. M., Miller, W. R., \& Lawendowski, L. A. (1999). The self-regulation questionnaire. In L. VandeCreek \& T. L. Jackson (eds.), Innovations in clinical practice: A source book, Vol. 17 (pp. 281-292). Professional Resource Press/Professional Resource Exchange.

Busse, V., \& Walter, C. (2013). Foreign language learning motivation in higher education: a longitudinal study of motivational changes and their causes. Modern Language Journal, 97(2), 435-456. https://doi.org/10.1111/j.1540-4781.2013.12004.x

Cheng, A., \& Lee, C. (2018). Factors affecting tertiary English learners' persistence in the selfdirected language learning journey. System, 76, 170-182. https://doi.org/10.1016/j.system.2018.06.001

Choi, E., \& Lee, J. (2018). EFL teachers' self-efficacy and teaching practices. ELT Journal, 72(2), 175-186. https://doi.org/10.1093/elt/ccx046

Choi, Y., Zhang, D., Lin, C.-H., \& Zhang, Y. (2018). Self-regulated learning of vocabulary in English as a foreign language. Asian EFL Journal Quarterly, 20(1), 54-82.

Credé, M., Roch, S. G., \& Kieszczynka, U. M. (2010). Class attendance in college: a metaanalytic review of the relationship of class attendance with grades and student characteristics. Review of Educational Research, 80(2), 272-295. https://doi.org/10.3102\%2F0034654310362998

Creswell, J. W. (2012). Educational research: Planning, conducting, and evaluating quantitative and qualitative research $\left(4^{\text {th }}\right.$ ed.). Boston: Pearson Education.

Csapó, B. (2007). Research into learning to learn through the assessment of quality and organization of learning outcomes. Curriculum Journal, 18(2), 195-210. https://doi.org/10.1080/09585170701446044

Çakır, Ö., \& Alıcı, D. (2009). Seeing self as others see you: variability in self-efficacy ratings in student teaching. Teachers and Teaching, 15(5), 541-561. https://doi.org/10.1080/13540600903139555

Demirdaş, Ö., \& Bozdoğan, D. (2013). Foreign language anxiety and performance of language learners in preparatory classes. Turkish Journal of Education, 2(3), 4-13. http://doi.org/10.19128/turje.181060 
Erdogan, T., \& Senemoglu, N. (2016). Development and validation of a scale on self-regulation in learning (SSRL). SpringerPlus, 5(1). https://doi.org/10.1186/s40064-016-3367-y

Ferla, J., Valcke, M., \& Cai, Y. (2009). Academic self-efficacy and academic self-concept: Reconsidering structural relationships. Learning and Individual Differences, 19(4), 499-505. https://doi.org/10.1016/j.lindif.2009.05.004

Fryer, L. K., \& Oga-Baldwin, W. L. Q. (2017). One more reason to learn a new language: Testing academic self-efficacy transfer at junior high school. Frontline Learning Research, 5(4), 61-75. https://doi.org/10.14786/flr.v5i4.301

Fukuda, A. (2018). The Japanese EFL learners' self-regulated language learning and proficiency. Journal of Pan-Pacific Association of Applied Linguistics, 22(1), 65-87. https://doi.org/10.25256/PAAL.22.1.4

Gan, Z., Liu, F., \& Yang, C. C. R. (2020). Student-teachers' self-efficacy for instructing selfregulated learning in the classroom. Journal of Education for Teaching, 46(1), 120-123. https://doi.org/10.1080/02607476.2019.1708632

George, D., \& Mallery, P. (2019). IBM SPSS Statistics 25 step by step: A simple guide and reference $\left(15^{\text {th }}\right.$ ed.). New York: Routledge.

Ghonsooly, B., \& Ghanizadeh, A. (2013). Self-efficacy and self-regulation and their relationship: a study of Iranian EFL teachers. Language Learning Journal, 41(1), 6884. http://dx.doi.org/10.1080/09571736.2011.625096

Gottfried, M. A. (2009). Evaluating the relationship between student attendance and achievement in urban elementary and middle schools: an instrumental variables approach. American Educational Research Journal, 47(2), 434-465. https://doi.org/10.3102/0002831209350494

Graham, S., \& Perin, D. (2007). Writing next: Effective strategies to improve writing of adolescents in middle and high schools. A report to Carnegie Corporation of New York. Washington, DC: Alliance for Excellent Education.

Hancı-Yanar, B., \& Bümen, N. T. (2012). İngilizce ile ilgili özyeterlik inancı ölçeğinin geliştirilmesi [Developing a self-efficacy scale for English]. Kastamonu Education Journal, 20(1), 97-110. https://dergipark.org.tr/tr/download/article-file/806921

Hewitt, E., \& Stephenson, J. (2012). Foreign language anxiety and oral exam performance: a replication of Phillips's MLJ study. Modern Language Journal, 96(2), 170-189. https://doi.org/10.1111/j.1540-4781.2011.01174.x

Honicke, T., \& Broadbent, J. (2016). The influence of academic self-efficacy on academic performance: a systematic review. Educational Research Review, 17, 63-84. https://doi.org/10.1016/j.edurev.2015.11.002

Horwitz, E. K., Horwitz, M. B., \& Cope, J. (1986). Foreign language classroom anxiety. Modern Language Journal, 70(2), 125-132. https://doi.org/10.2307/327317

Huang, Y., \& Zhang, L. J. (2020). Does a process-genre approach help improve students' argumentative writing in English as a foreign language? Findings from an intervention study. Reading \& W W Quarterly, 36(4), 339-364. https://doi.org/10.1080/10573569.2019.1649223

Jee, M. J. (2018). Foreign language anxiety in relation to affective variables: Learners of Korean as a foreign language in Australia. Australian Review of Applied Linguistics, 41(3), 328-348. https://doi.org/10.1075/aral.17068.jee

Kelsen, B. A., \& Liang, H.-Y. (2012). Indicators of achievement in EFL classes at a Taiwanese university. Education Research 2012. https://doi.org/10.1155/2012/635964

Kesen-Mutlu, A., Andarab, M. S., \& Karacan, C. G. (2019). Self-efficacy and the use of compensatory strategies: a study on EFL learners. European Journal of Educational Research, 8(1), 249-255. http://doi.org/10.12973/eu-jer.8.1.249 
Kim, D.-H., Wang, C., Ahn, H. S., \& Bong, M. (2015). English language learners' self-efficacy profiles and relationship with self-regulated learning strategies. Learning and Individual Differences, 38, 136-142. https://doi.org/10.1016/j.lindif.2015.01.016

Liem, A. D., Lau, S., \& Nie, Y. (2008). The role of self-efficacy, task value, and achievement goals in predicting learning strategies, task disengagement, peer relationship, and achievement outcome. Contemporary Educational Psychology, 33(4), 486-512. https://doi.org/10.1016/j.cedpsych.2007.08.001

Macaro, E., \& Akincioglu, M. (2018). Turkish university students' perceptions about English Medium Instruction: Exploring year group, gender and university type as variables. Journal of Multilingual and Multicultural Development, 39(3), 256-270. https://doi.org/10.1080/01434632.2017.1367398

McInerney, D. M. (2008). The motivational roles of cultural differences and cultural identity in self-regulated learning. In D. H. Schunk \& B. J. Zimmerman (Eds.), Motivation and self-regulated learning: Theory, research, and applications (p. 369-400). Lawrence Erlbaum Associates Publishers.

Mills, N., Pajares, F., \& Herron, C. (2007). Self-efficacy of college intermediate French students: Relation to achievement and motivation. Language Learning, 57(3), 417442. https://doi.org/10.1111/j.1467-9922.2007.00421.x

Munira, S. (2017). Effect of process oriented activities on English production skills of Bangladeshi EFL learners: a study on the freshers of Green University of Bangladesh. Journal of Education and Social Sciences, 6(2), 107-119.

Nyamapfene, A. (2010). Does class attendance still matter? Engineering Education, 5(1), 6474. https://doi.org/10.11120/ened.2010.05010064

Ozer, O. (2020). Lecturers' experiences with English-medium instruction in a state university in Turkey: Practices and challenges. Issues in Educational Research, 30(2), 612-634.

Ozer, O., \& Tanrıseven, I. (2016). The effect of portfolio-based writing assessment on the development of writing skills of EFL students. International Online Journal of Educational Sciences, 8(3), 35-45.

Passiatore, Y., Pirchio, S., Oliva, C., Panno, A., \& Carrus, G. (2019). Self-efficacy and anxiety in learning English as a foreign language: Singing in class helps speaking performance. Journal of Educational, Cultural and Psychological Studies, 20, 121-138. https://doi.org/10.7358/ecps-2019-020-passi

Pasupathy, R., \& Siwatu, K. O. (2014). An investigation of research self-efficacy beliefs and research productivity among faculty members at an emerging research university in the USA. Higher Education Research \& Development, 33(4), 728-741. http://dx.doi.org/10.1080/07294360.2013.863843

Piniel, K., \& Csizér, K. (2013). L2 motivation, anxiety and self-efficacy: The interrelationship of individual variables in the secondary school context. Studies in Second Language Learning and Teaching, 3(4), 523-550. https://doi.org/10.14746/ssllt.2013.3.4.5

Raoofi, S., Tan, B. H., \& Chan, S. H. (2012). Self-efficacy in second/foreign language learning $\begin{array}{llll}\text { contexts. English } \quad \text { Language } & \text { 60aching, }\end{array}$ http://dx.doi.org/10.5539/elt.v5n11p60

Reyes-Cruz, M. D. R., \& Perales-Escudero, M. D. (2016). Research self-efficacy sources and research motivation in a foreign language university faculty in Mexico: implications for educational policy. Higher Education Research \& Development, 35(4), 800-814. https://doi.org/10.1080/07294360.2015.1137884

Ryan, R. M., \& Deci, E. L. (2009). Promoting self-determined school engagement: Motivation, learning, and well-being. In K. R. Wentzel, \& A. Wigfield (eds.). Handbook on motivation at school (pp. 171-196). New York: Routledge. 
Salehi, M., \& Marefat, F. (2014). The effects of foreign language anxiety and test anxiety on foreign language test performance. Theory \& Practice in Language Studies, 4(5), 931940. http://doi.org/10.4304/tpls.4.5.931-940

Sarıçoban, A., \& Behjoo, B. M. (2016). Academic self-efficacy and prospective ELT teachers' achievement. Journal of Language and Linguistic Studies, 12(1), 55-62. http://www.jlls.org/index.php/jlls/article/view/468

Schunk, D. H. (2001). Social cognitive theory and self-regulated learning. In B. J. Zimmerman \& D. H. Schunk (eds.), Self-regulated learning and academic achievement: Theoretical perspectives (pp. 125-151). Lawrence Erlbaum Associates Publishers.

Seker, M. (2016). The use of self-regulation strategies by foreign language learners and its role in language achievement. Language Teaching Research, 20(5), 600-618. https://doi.org/10.1177/1362168815578550

Shing, L. S., \& Rameli, M. R. M. (2020). The influence of self-regulation towards academic achievement in English among Malaysian upper primary students. Universal Journal of Educational Research, 8(5A), 1-11. http://doi.org/10.13189/ujer.2020.081901

Shirvan, M. E., Khajavy, G. H., Nazifi, M., \& Taherian, T. (2018). Longitudinal examination of adult students' self-efficacy and anxiety in the course of general English and their prediction by ideal self-motivation: Latent growth curve modelling. New Horizons in Adult Education \& Human Resource Development, 30(4), 23-41. https://doi.org/10.1002/nha3.20230

Shirvan, M. E., \& Talebzadeh, N. (2018). Foreign language anxiety and enjoyment in an imagined community. Eurasian Journal of Applied Linguistics, 4(2), 109-133. https://doi.org/10.32601/ejal.464043

Thompson, G., \& Woodman, K. (2019). Exploring Japanese high school English teachers' foreign language teacher efficacy beliefs. Asia-Pacific Journal of Teacher Education, 47(1), 48-65. https://doi.org/10.1080/1359866X.2018.1498062

Torres, K. M., \& Turner, J. E. (2016). Students' foreign language anxiety and self-efficacy beliefs across different levels of university foreign language coursework. Journal of $\begin{array}{llll}\text { Spanish } \quad \text { Language } & \text { 57-73), }\end{array}$ https://doi.org/10.1080/23247797.2016.1163101

Trang, T. T. T., Baldauf Jr., R. B., \& Moni, K. (2013). Investigating the development of foreign language anxiety: an autobiographical approach. Journal of Multilingual and Multicultural Development, 34(7), 709-726. http://dx.doi.org/10.1080/01434632.2013.796959

Wang, C.-H., Harrison, J., Cardullo, V., \& Lin, X. (2018). Exploring the relationship among international students' English self-efficacy, using English to learn self-efficacy, and academic self-efficacy.Journal of International Students, 8(1), 233-250. https://doi.org/10.5281/zenodo.1134299

Wang, C., Kim, D. H., Bai, R., \& Hu, J. (2014). Psychometric properties of a self-efficacy scale for English language learners in China. System, 44, 24-33. https://doi.org/10.1016/j.system.2014.01.015

Woodrow, L. (2006). Anxiety and speaking English as a second language. RELC Journal, 37(3), 308-328. https://doi.org/10.1177/0033688206071315

Yabukoshi, T. (2018). Self-regulation and self-efficacy for the improvement of listening proficiency outside the classroom. Language Learning Journal. https://doi.org/10.1080/09571736.2018.1472626

Yağı, O. (2018). An adaptation study of the measure of pronunciation anxiety in the foreign language classroom into Turkish language and culture. Kastamonu Education Journal, 26(5), 1519-1526. https://doi.org/10.24106/kefdergi.2133 
Yan, C., \& He, C. (2019). Why do final-year student teachers skip classes? A Chinese perspective. Compare: A Journal of Comparative and International Education, 49(1), 81-97. https://doi.org/10.1080/03057925.2017.1385389

Yan, J. X., \& Horwitz, E. K. (2008). Learners' perceptions of how anxiety interacts with personal and instructional factors to influence their achievement in English: a qualitative analysis of EFL learners in China. Language Learning, 58(1), 151-183. https://doi.org/10.1111/j.1467-9922.2007.00437.x

Zheng, Y., \& Cheng, L. (2018). How does anxiety influence language performance? From the perspectives of foreign language classroom anxiety and cognitive test anxiety. Language Testing in Asia, 8(13). https://doi.org/10.1186/s40468-018-0065-4 